\title{
Tight gas production model considering TPG as a function of pore pressure, permeability and water saturation
}

\author{
Atif Zafar ${ }^{1,2} \cdot$ Yu-Liang Su ${ }^{1} \cdot$ Lei Li $^{1} \cdot$ Jin-Gang Fu ${ }^{1} \cdot$ Asif Mehmood $^{1} \cdot$ Wei-Ping Ouyang ${ }^{3} \cdot$ Mian Zhang ${ }^{3}$
}

Received: 28 January 2019 / Published online: 5 March 2020

(c) The Author(s) 2020

\begin{abstract}
Threshold pressure gradient has great importance in efficient tight gas field development as well as for research and laboratory experiments. This experimental study is carried out to investigate the threshold pressure gradient in detail. Experiments are carried out with and without back pressure so that the effect of pore pressure on threshold pressure gradient may be observed. The trend of increasing or decreasing the threshold pressure gradient is totally opposite in the cases of considering and not considering the pore pressure. The results demonstrate that the pore pressure of tight gas reservoirs has great influence on threshold pressure gradient. The effects of other parameters like permeability and water saturation, in the presence of pore pressure, on threshold pressure gradient are also examined which show that the threshold pressure gradient increases with either a decrease in permeability or an increase in water saturation. Two new correlations of threshold pressure gradient on the basis of pore pressure and permeability, and pore pressure and water saturation, are also introduced. Based on these equations, new models for tight gas production are proposed. The gas slip correction factor is also considered during derivation of this proposed tight gas production models. Inflow performance relationship curves based on these proposed models show that production rates and absolute open flow potential are always be overestimated while ignoring the threshold pressure gradients.
\end{abstract}

Keywords Inflow performance relationship · Pore pressure - Threshold pressure gradient $\cdot$ Tight gas field development · Tight gas sand reservoir

\section{Introduction}

There is an increase in the development of tight sandstone reservoirs for the last couple of decades. Due to this increasing demand, understanding the flow mechanism of such reservoirs has achieved a great interest. Particularly, the

Edited by Yan-Hua Sun

Yu-Liang Su

suyuliang@upc.edu.cn

Atif Zafar

atif_zafar1984@yahoo.com

1 School of Petroleum Engineering, China University of Petroleum (East China), Qingdao 266580, Shandong, China

2 Department of Petroleum Technology, University of Karachi, University Road, Karachi 75270, Pakistan

3 Changqing Downhole Technology Company, Chuangqing Drilling Engineering Co., Ltd, CNPC, Xi' an 710018, Shaanxi, China threshold pressure gradient (TPG) is an important parameter of a tight gas reservoir (Civan 2017). TPG is the pressure gradient that allows the fluid to become movable against the viscous forces. These viscous forces are found between solid and gas and are one of the main reasons for deviation of gas flow from Darcy or linear flow (Liu 2019; Liu et al. 2019; Yan et al. 1990). As shown in Fig. 1, the ideal Darcy flow has a linear relationship with the pressure gradient with the trend line passing through the origin. However, in low to ultra-low permeable porous media, the gas flow does not obey the Darcy law and converts to non-Darcy flow. One of the most important characteristics of non-Darcy flow is; at very small pressure gradient non-Darcy flow velocity is always lower than Darcy flow velocity (Wang and Sheng $2017 \mathrm{a}, \mathrm{b})$. As a result, a nonlinear segment appears in the flow rate-pressure gradient curve. In Fig. 1, by definition, the intersection point of the non-Darcy curve and $x$-axis (pressure gradient) is TPG. Although the low-velocity non-Darcy flow curve becomes approximately linear at higher pressure gradient but on the backward extrapolation of this linear trend, it does not pass through the origin as shown in Fig. 1. 


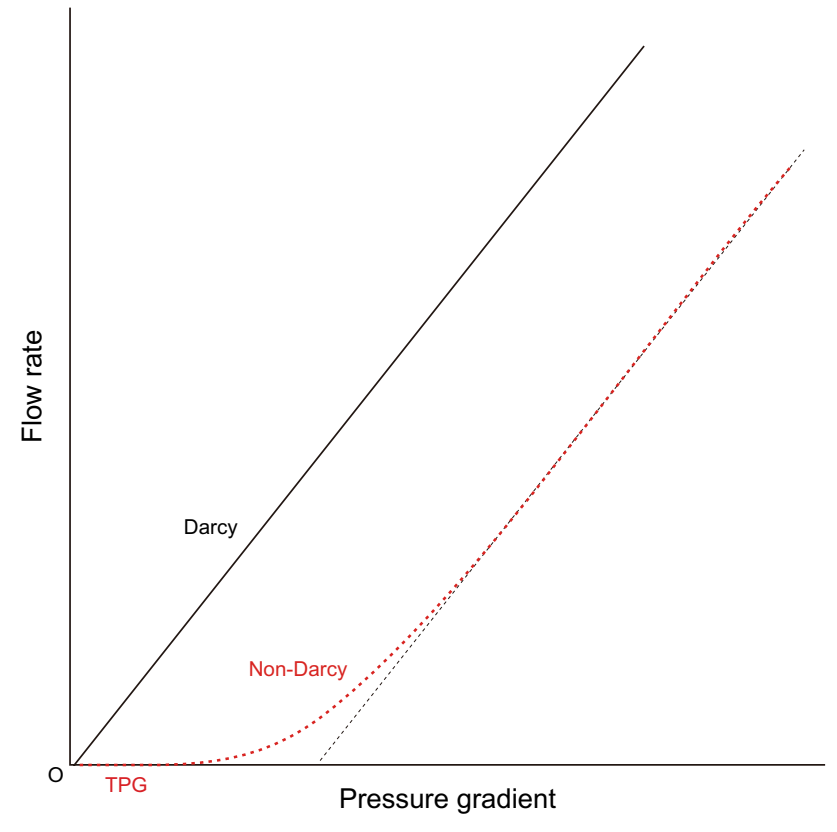

Fig. 1 A schematic of typical flow behavior with TPG

The main cause of this low-velocity nonlinear flow is the boundary effect between solid (rock) and fluid (liquid and/ or gas). When the interface between solid and fluid phases is large, the surface attraction force becomes more essential to consider. While this surface attraction force is indirectly proportional to permeability, i.e., low permeable porous media has greater attraction force between solid rock and fluid (Wu et al. 2019). Jamin effect is also considered as one of the main causes of the existence of TPG in gas reservoirs (Tian et al. 2018).

It is also a well-established fact that TPG exists in both single-phase and two-phase fluid reservoirs. It is due to the interaction between the solid phase (rock) and fluid (oil, gas, water). The different fluid saturations just affect the TPG, not the main cause of the existence of this phenomenon (Dong et al. 2019; Miller and Low 1963; Zhao et al. 2014).

As TPG is one of the vital components to understand the nonlinear flow in the unconventional reservoir, it has been investigated for a long period (Bennion et al. 2000; Civan 2008; Dong et al. 2019; Liu 2019; Liu et al. 2019). Li et al. (2008) and Yang et al. (2015) showed through different experiments that the seepage curve has a nonlinear relationship under low flow velocity. Initially, it was assumed that TPG remains constant (Civan 2013) but recent progress in this regard showed that TPG changes along with permeability. Zhu et al. (2011) observed that TPG increases in both cases either permeability decreases or water saturation increases but they did not offer any definite correlation. Feng et al. (2008) offered a mathematical model for unsteady seepage of gas while ignoring the influencing factors of TPG.

Many researchers have also conducted research on heterogeneous tight gas reservoirs having low-velocity non-Darcy flow (Rezaee et al. 2013; Song et al. 2014; Xiao et al. 2016). But they did not reflect the characteristics of heterogeneous reservoirs in their experiments and models. Wang and Sheng (2017a, b) suggested that the non-Darcy flow of low-velocity profile greatly affects the well production performance. Cao et al. (2018) offered a composite transient model for horizontal well testing while Diwu et al. (2018) developed a model for well test pressure transient analysis by incorporating the TPG. Even some scholars offered mathematical production models for heterogeneous tight reservoirs (Chen and Durlofsky 2006; Wang et al. 2018; Wu et al. 2006) and some have also worked on relative permeability, water saturation and capillary pressure considering the heterogeneity of porous media. But these studies are based on Darcy flow.

Although reasonable progress has been made in this field, there is still a need for some improvement in many aspects. Many pieces of research have already proved the existence of TPG in tight and ultra-tight reservoirs (Wu et al. 2019; Xiao et al. 2016; Ye et al. 2019; Zhou 2019). There is relatively less research has been carried out for TPG of a gas reservoir as compared to TPG of oil reservoir (Zeng et al. 2018). Note that, since gas flow in a tight reservoir highly affected by the slippage effect, therefore results of the conventional TPG test for gas reservoirs cannot be accurate. Because these conventional tests are performed under atmospheric pressure, whereas for correct measurement of TPG of a tight gas reservoir in the laboratory, reservoir conditions should be maintained like confining pressure, back pressure, etc. Another lacking in the previous research regarding heterogeneous tight gas reservoir is that the previous work does not consider reservoir heterogeneities.

The most important parameter of the heterogeneous tight gas reservoir is permeability which is found to be distributed in a reservoir in different ranges values. Water saturation is also the main parameter and found to be high in the case of the tight gas reservoir. Pore pressure also influences the TPG. Therefore, further work regarding TPG of ultra-low permeable and tight sandstone gas reservoirs is essential.

In our study, first of all, the experimental procedure was specially designed in which confining pressure and back pressure were set to observe the effects of different pore pressures on TPG. Secondly, the flow experiments were carried out at different permeability and water saturation. Thirdly, TPG correlations in terms of permeability and water saturation were obtained separately. Finally, gas flow rate models are offered by considering the TPG, diffusion and non-Darcy effects. In addition, the applications of these new models using actual reservoir properties are also discussed. 


\section{Experimental material and procedures}

\subsection{Experimental materials}

Experiments were performed on natural cores obtained from the Peer gas field, which is located in L-Basin of Pakistan. This is an ultra-low permeable, tight sandstone gas reservoir. The permeability of these cores was already measured by the pulse decay method (PDM) for accuracy. In the computerized PDM instrument, the core sample was installed in the core holder which was connected to the chambers at both ends. Initially, the pressure was set to $20 \mathrm{MPa}$ and then some pressure pulse was applied on upstream chambers. The permeability results were generated on the basis of recorded pressure variations in both ended chambers (upstream and downstream). The PDM is more suitable for measuring the permeability of tight formations compared to the steady stead method (Wang et al. 2018; Yang et al. 2019). Table 1 shows the properties of the cores. Table 2 shows the properties of water which was prepared as per the actual properties of the formation water of the study area. The gas used in these experiments was methane with $99.99 \%$ purity. The temperature was set to $83{ }^{\circ} \mathrm{C}$ (as per the actual reservoir temperature of the study area).

Table 1 Properties of the natural cores used

\begin{tabular}{lllll}
\hline Core number & Diameter, cm & Length, cm & Porosity, $\%$ & $\begin{array}{l}\text { Perme- } \\
\text { ability, } \\
10^{-3} \mu \mathrm{m}^{2}\end{array}$ \\
\hline 1 & & & & 0.0141 \\
2 & 2.540 & 4.880 & 1.09 & 0.4989 \\
3 & 2.540 & 4.880 & 6.93 & 0.0156 \\
4 & 2.480 & 5.000 & 2.99 & 0.0952 \\
5 & 2.490 & 5.220 & 3.18 & 0.1192 \\
6 & 2.530 & 6.150 & 3.98 & 0.1121 \\
7 & 2.540 & 4.890 & 1.81 & 0.1223 \\
8 & 2.490 & 3.980 & 4.89 & 0.1399 \\
9 & 2.490 & 3.970 & 4.47 & 0.2299 \\
10 & 2.540 & 6.150 & 5.46 & 0.1598 \\
11 & 2.540 & 3.840 & 4.92 & 0.2239 \\
\hline
\end{tabular}

\subsection{Experimental procedures}

Figure 2 shows a schematic diagram of the experimental setup for TPG measurements, mainly consisting of pressure pumps, pressure sensors, a flow meter, a flow controller, a core holder and a cylinder. The experimental procedures are as follows:

(1) Make the natural core vacuumed and record the weight. Saturate the natural core with already prepared formation water and weigh the core.

(2) Install the core in the core holder and start to inject the gas $\left(\mathrm{CH}_{4}\right)$ to achieve the prescribed value of water saturation.

(3) Apply the back pressure (pore pressure) to the desired value and start to infill the gas. When the flow from the outlet becomes constant and the gas flow rate stabilizes, measure it.

(4) Resume inject the gas at a little higher injection pressure. Record the value of the gas rate when the flow stabilizes.

(5) Repeat procedure from step (1) to step (4) to investigate the effects of permeability and water saturation by replacing cores.

During the experiment, the water saturation was maintained throughout the process by making sure that it is a single gas flow so that reservoir conditions may be matched positively. Note that, the injection pressure should be increased slowly to avoid the water flow from the experimental core because, at higher differential pressure, the water phase will start flowing.

\section{Results and discussion}

\subsection{Non-Darcy flow}

Core 3 was used with water saturation of $62 \%$ in order to investigate non-Darcy flow behavior. No back pressure was applied to the system and the confining pressure was set to $43 \mathrm{MPa}$. Experimental data are plotted in Fig. 3 which shows the nonlinear flow behavior of gas in the tight sandstone. Initially, the gas flow rate was relatively very small. This was due to a low pressure gradient. The curve plotted

Table 2 Properties of formation water of Peer gas reservoir

\begin{tabular}{|c|c|c|c|c|c|c|c|c|c|c|c|}
\hline \multirow[t]{2}{*}{$\mathrm{pH}$} & \multirow[t]{2}{*}{ Density, $\mathrm{g} / \mathrm{cm}^{3}$} & \multirow[t]{2}{*}{ Resistivity, $\Omega \mathrm{m}$} & \multicolumn{7}{|c|}{ Ion concentration, $\mathrm{g} / \mathrm{L}$} & \multirow[t]{2}{*}{ Total salinity, g/L } & \multirow[t]{2}{*}{ Genetic type } \\
\hline & & & $\mathrm{Na}^{+}+\mathrm{K}^{+}$ & $\mathrm{Cl}^{-}$ & $\mathrm{Ca}^{2+}$ & $\mathrm{Mg}^{2+}$ & $\mathrm{SO}_{4}{ }^{2-}$ & $\mathrm{HCO}_{3}^{-}$ & $\mathrm{Fe}^{2+}$ & & \\
\hline 6.57 & 0.157 & 0.08 & 5.914 & 97.5 & 76 & 8.7 & 0.496 & 1.03 & 0.00057 & 285.72 & $\mathrm{Cl}-\mathrm{Ca}$ \\
\hline
\end{tabular}




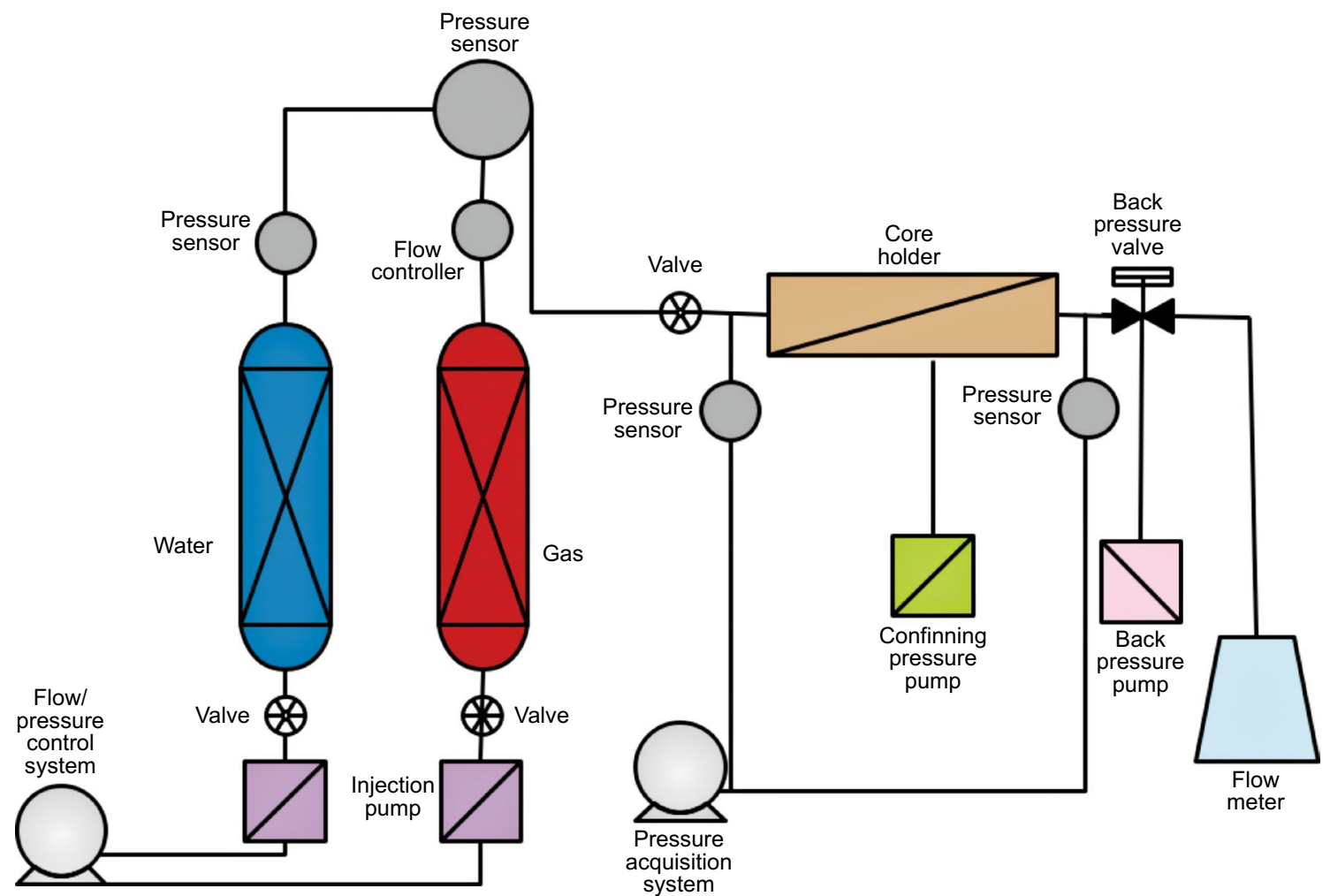

Fig. 2 Schematic diagram of the experimental setup for measuring TPG

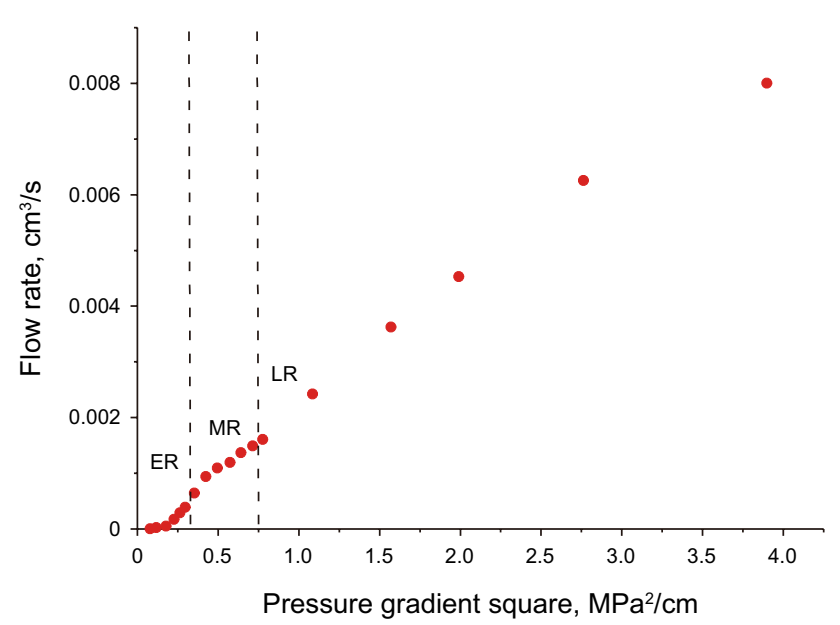

Fig. 3 Flow rate curve of Core 3

in Fig. 3 can be categorized into three regions for a better understanding of flow mechanisms and factors affecting the flow in tight porous media.

\subsubsection{Early region (ER)}

In fact, due to the force of attraction between the two phases, there is a boundary layer near the solid wall that has a great impact on the fluid-solid interaction by occupying the flow space and lowering down the flow rate. The thickness of this boundary layer is indirectly proportional to the pressure gradient (Wu et al. 2017; Xiong et al. 2017). Since in this region, the pressure gradient is very small; therefore, the impact of this boundary layer is more obvious. In the beginning, the flow rate is very low and shows the nonlinear flow trend which is the basic definition of TPG.

Another reason for this nonlinear start-up is the Jamin effect which occurs when the pore throat radius is relatively smaller than the gas bubble radius (Tian et al. 2018). Since the pressure gradient is quite lower in this region, therefore, the gas flow rate cannot pass through the Jamin effect until the pressure gradient reaches to TPG, i.e., the largest pores allow the gas to flow (Sakhaee and Bryant 2014). As can be clearly seen from Fig. 3 that in the early region, after passing through the Jamin effect, the gas flow rate increases slowly as a function of pressure gradient square. 


\subsubsection{Middle region (MR)}

The middle region is mainly influenced by the slippage effect. It can be seen from Fig. 3 that in this region, there is relatively a little higher slope of flow rate increasing trend for a while. This is due to the slippage effect which is a non-Darcy phenomenon that occurs during the non-laminar flow regime. This effect happens in tight to ultra-tight porous media when the average pore throat size becomes identical to the mean free path of the molecules of the gas. Due to this, when interacting with the pore walls, gas molecules move faster and create a slippage effect. By enhancing the permeability, slippage improves the velocity of gas molecules at the pore wall. This velocity enhancement effect remains limited to the pore wall, which means it does not occur at the pore center (Klinkenberg 1941; Wang et al. 2019).

The slippage phenomenon is declining in the middle region of Fig. 3 as the pressure gradient square increasing. As a result, the apparent incremental trend of the gas flow rate tended higher to lower. While observing the slippage effect from Fig. 3, note that the back pressure was not applied yet in this section of the experiment.

\subsubsection{Late region (LR)}

When the pressure difference greater than the middle region the late region appears. This can be seen from Fig. 3 that in the late region, the rate of increasing gas flow against the pressure gradient square is approximately linear. However, the backward extrapolation of this linear trend does not meet the origin that makes it non-Darcy flow.

\subsection{Effect of pore pressure}

The previous research regarding low permeability/ultra-low permeability/tight reservoirs has shown that the differential pressure of external and internal core pressure directly affects the pore structure and only bigger pore throats contribute in the flow at TPG ( $\mathrm{Li}$ et al. 2019a; Sakhaee and Bryant 2014). In this portion, we aim at studying the effects of pore pressure on TPG. For this purpose, experiments were performed by applying different pore pressures. The overburden pressure (confining pressure) was always higher than the pore pressure (back pressure) so that the stress may have remained unchanged. In this way, the effects of permeability variations were eliminated. Experiments were performed on cores $1,3,4,5,6$ with the same water saturation (45\%) by applying various pore pressures (Fig. 4).

Figure 4 demonstrates that when the pore pressure is lower, TPG increases as the increment of pore pressure and when the pore pressure is higher enough, the TPG remains unchanged. This is because of the slippage effect. In tight sandstones, the slippage effect has a high influence on flow,

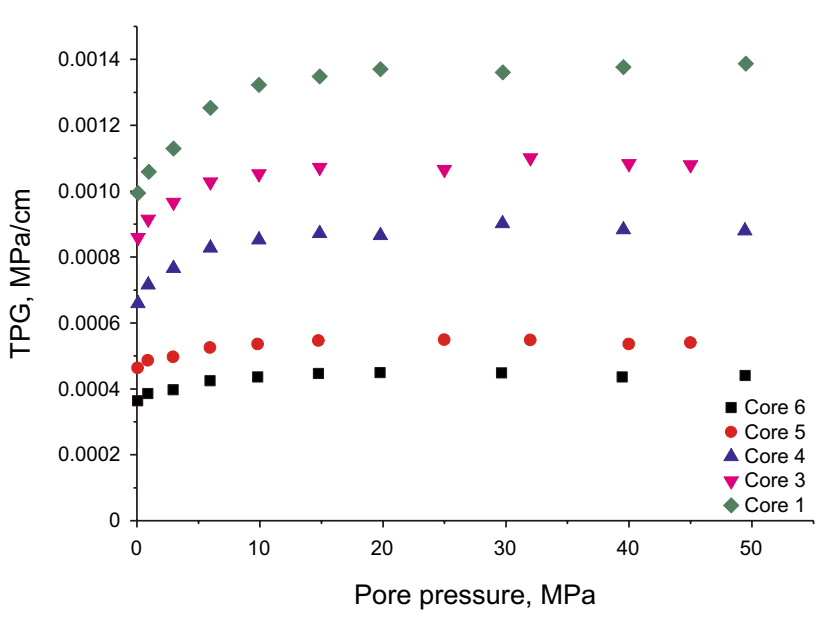

Fig. 4 TPG versus pore pressure (variable overburden pressure)

resulting in the higher flow rate and the higher apparent permeability. At higher pore pressure, the slippage effect becomes weaker. Figure 4 also demonstrates that, for higher permeability cores, the TPG has lower-amplitude change as compared to relatively lower permeability cores. That is mainly because, in the case of lower permeability, the slippage effect is more active and its influence on TPG is thus greater than that of relatively high permeability cores.

\subsection{Effect of permeability}

In order to observe the effects of permeability, experiments were designed and performed as per the manner that reservoir conditions may be simulated, i.e., fixed overburden pressure (confining pressure) and variable pore pressure (back pressure). Cores 1-11 were used, with water saturation of 50\%. The effects of permeability change on TPG at different pore pressures is shown in Fig. 5. The trend is the opposite as compared to Fig. 4 because, in this section, the effective stress exerted on experimental cores is not constant. So, the permeability decreases because of the decrease in pore pressure, and the pore pressure decreases due to the increment of effective stress. While the effective stress increases due to fixed confining pressure.

Figure 5 shows the power relationship curve between TPG $\left(G_{\mathrm{p}}\right)$ and pore pressure $\left(p_{\mathrm{f}}\right)$ as a function of permeability. Based on this, a general correlation is developed (Eq. 1).

$G_{\mathrm{p}}=a\left(p_{\mathrm{f}}\right)^{b}$

where $G_{\mathrm{p}}$ is the threshold pressure gradient; $p_{\mathrm{f}}$ is the pore pressure; $a$ and $b$ are fitting coefficients. Eleven sets of power coefficients $a$ and $b$ were obtained by fitting, and the trend of these parameters is also discovered (Fig. 6). Then, a new mathematical correlation that incorporates the effects of 


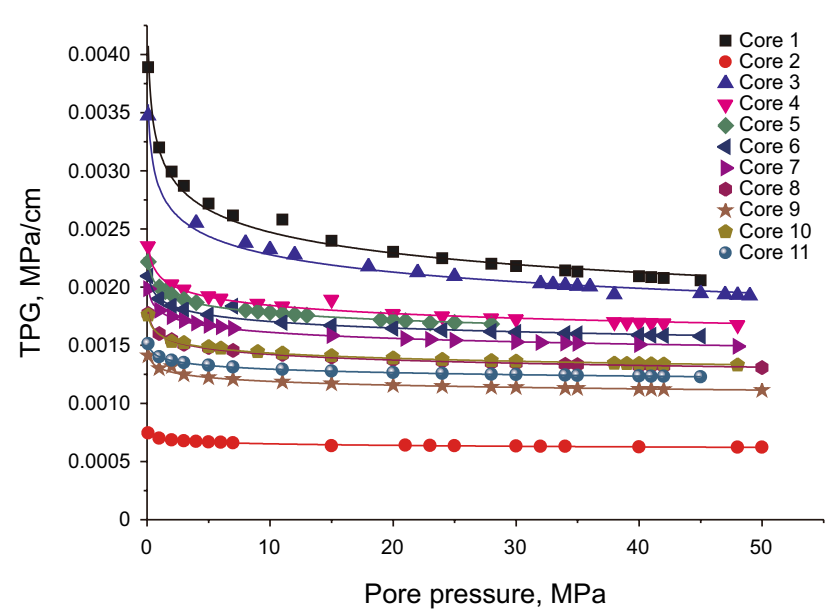

Fig. 5 TPG versus pore pressure (fixed overburden pressure)

permeability and pore pressure on TPG was established as follows:

$G_{\mathrm{p}}=\left(9.69 \times 10^{-4} k_{\mathrm{a}}^{-0.2741}\right) p_{\mathrm{f}}^{\left(0.02371 k_{\mathrm{a}}^{-0.3407}\right)}$

where $k_{\mathrm{a}}$ is the absolute permeability of the cores.

\subsection{Effect of water saturation}

To investigate the influence of water saturation on TPG as a function of pore pressure, experiments were performed on core 1. Various water saturation values were used. The results are shown in Fig. 7 which demonstrates that cores having higher water saturation have relatively higher TPG and vice versa.

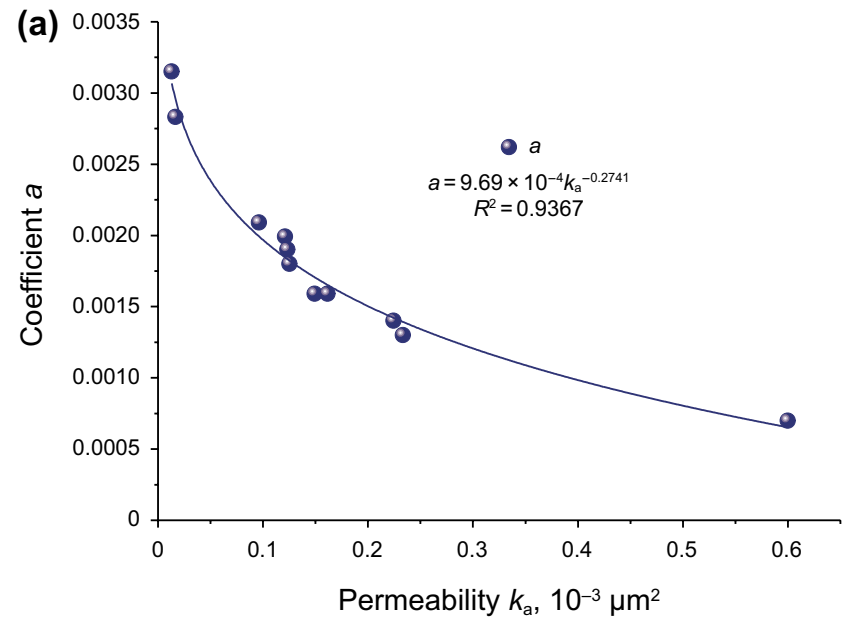

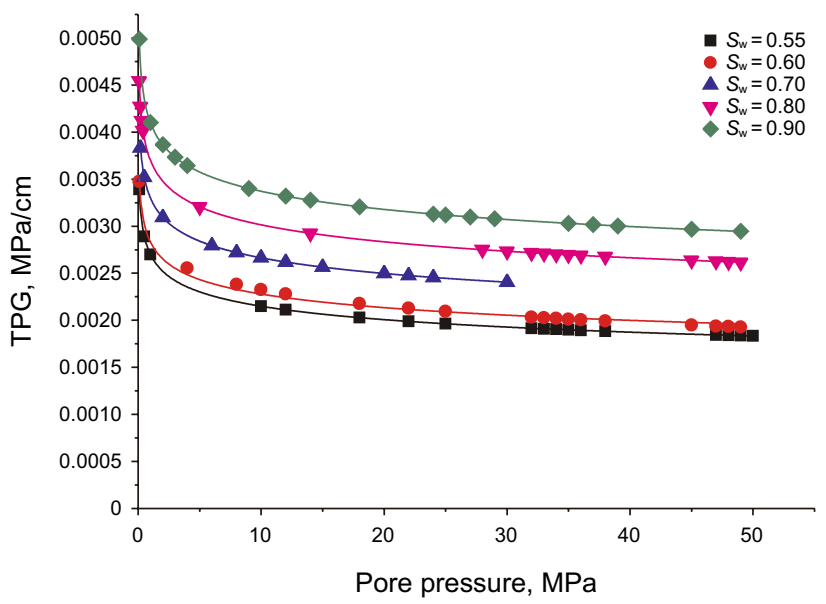

Fig. 7 TPG versus pore pressure at different water saturation values

Figure 7 shows the power relationship curve between TPG and pore pressure as a function of water saturation. Based on this, a general correlation is developed (Eq. 3).

$G_{\mathrm{p}}=a_{1}\left(p_{\mathrm{f}}\right)^{b_{1}}$

where $a_{1}$ and $b_{1}$ are fitting coefficients. Five data sets of fitting coefficients $a_{1}$ and $b_{1}$ were achieved by analyses, and the trend of these parameters is also discovered (Fig. 8). Then, a new mathematical correlation that incorporates the effects of water saturation and pore pressure on TPG is established as follows:

$G_{\mathrm{p}}=\left(4 \times 10^{-3} S_{\mathrm{w}}+0.5 \times 10^{-3}\right) p_{\mathrm{f}}^{\left(0.04 S_{\mathrm{w}}-0.121\right)}$

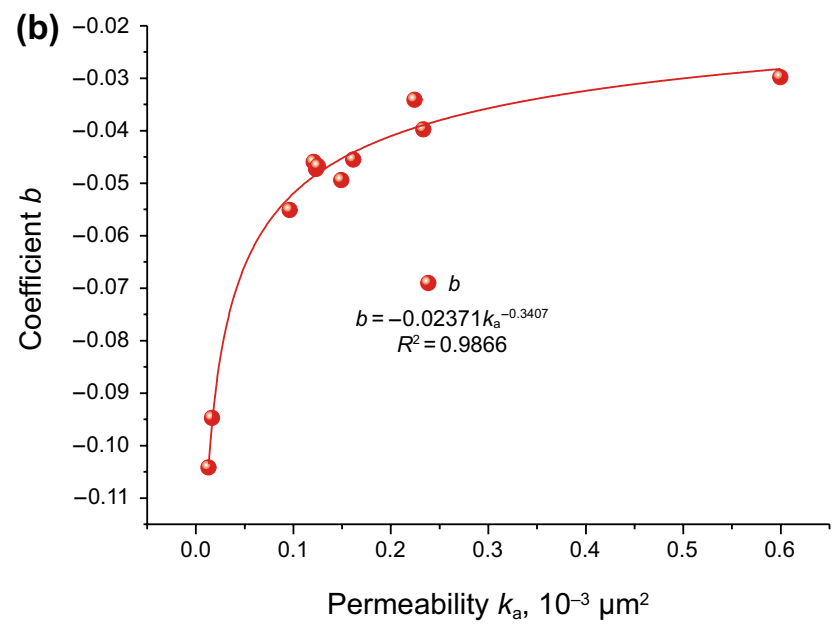

Fig. 6 a Fitting coefficient $a$. b Fitting coefficient $b$ 

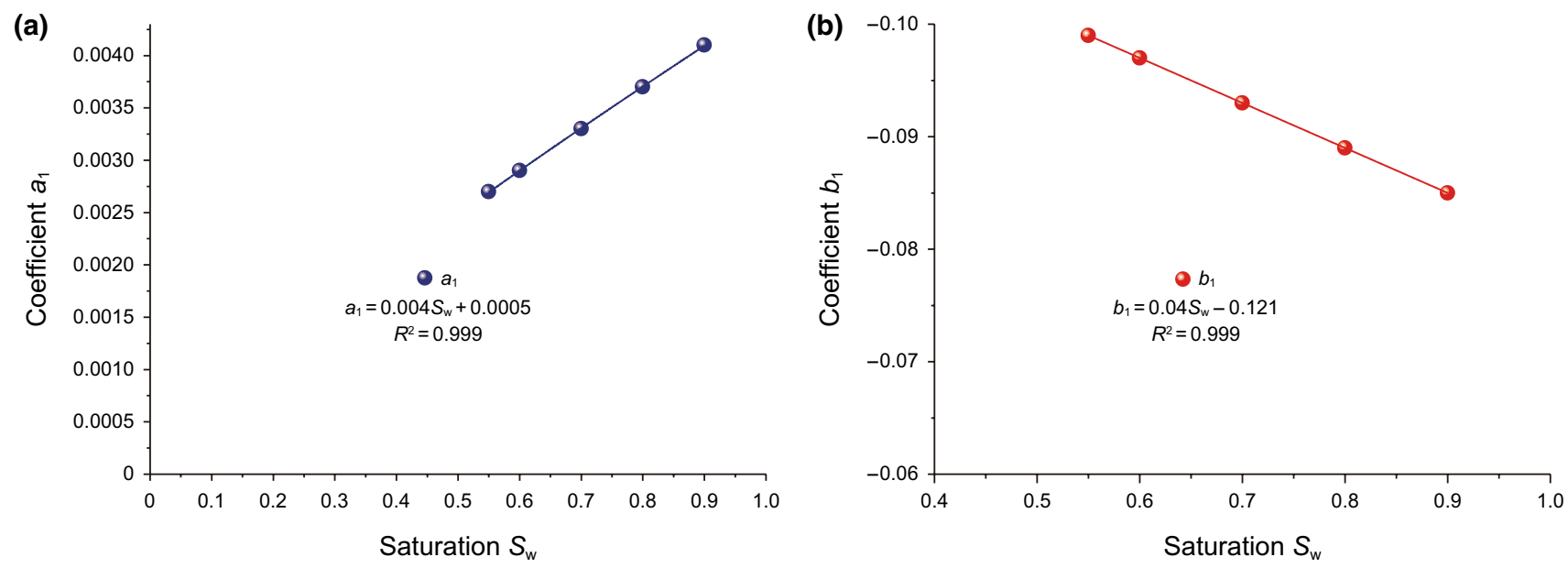

Fig. 8 a Fitting coefficient $a_{1}$. b Fitting coefficient $b_{1}$

\section{Production model including TPG}

This is a well-established fact that under low velocity and low pressure, an effect is always present there, namely gas Klinkenberg effect (Liang et al. 2016; Moghaddam and Jamiolahmady 2016; Nakhli et al. 2017). To address these effects, Beskok and Karniadakis (1999) offered a rigorous gas flow equation (Deng et al. 2014; Liu et al. 2018):

$v=\frac{k_{\mathrm{a}} k_{\mathrm{rg}}}{\bar{\mu}}\left(f_{\mathrm{c}}\right)\left(\frac{\mathrm{d} p}{\mathrm{~d} r}-G_{\mathrm{p}}\right)$

where $f_{\mathrm{c}}$ is the correction factor shown as Eq. 6 and it depends upon Knudsen number (Kn) (Eq. 7):

$f_{\mathrm{c}}=[1+\alpha(K n) K n]\left(1+\frac{4 K n}{1-b K n}\right)$

$K n=\frac{\lambda}{r}$

Knudsen number $(\mathrm{Kn})$ is a dimensionless parameter and it is used to categorize flow regimes especially in unconventional porous media or small pores where deviation from the viscous flow is significant. It depends upon the molecular mean free path, $\lambda(\mathrm{nm})$ and radius of the pore, $r(\mathrm{~nm})$ (Eq. 9). $\lambda$ is the average distance covered by molecules between collision and calculated by the following equation (Bird 1976; Cussler 1997):

$\lambda(\bar{p}, T)=\frac{\mu}{\bar{p}} \sqrt{\frac{\pi R_{\mathrm{g}} T}{M}}$

where $R_{\mathrm{g}}$ is the universal gas constant and its value is 8.314 $\mathrm{J} \mathrm{mol}^{-1} \mathrm{~K}^{-1} ; M$ is the molecular weight of gas; $\bar{p}$ and $T$ are pressure and temperature in $\mathrm{Pa}$ and $\mathrm{K}$, respectively. $r=8.86 \times 10^{-2} \sqrt{\frac{k}{\phi}}$

where $k$ is permeability, $\mu \mathrm{m}^{2}$; and $\phi$ is porosity in fraction. By using data of Loyalka and Hamoodi (1990), Beskok and Karniadakis (1999) established the following correlation for gas rarefaction coefficient $(\alpha)$ :

$\alpha=\alpha_{0} \frac{2}{\pi} \tan ^{-1}\left(\alpha_{1} K n^{\alpha_{2}}\right)$

here the values of $\alpha_{1}$ and $\alpha_{2}$ are 4 and 0.4, respectively, and $\alpha_{0}$, representing free molecular flow condition, is an asymptotic upper limit value of $\alpha$ as $K n \rightarrow \infty$, given by (Beskok and Karniadakis 1999):

$\alpha_{0}=\alpha_{K n \rightarrow \infty}=\frac{64}{3 \pi\left(1-\frac{4}{b}\right)}$

where $b$ is a slip coefficient and in the slip flow, $\alpha=0$ and $b=-1$, so Eq. 11 becomes

$\alpha_{0}=\frac{64}{15 \pi}$

In terms of volumetric flow, Eq. 5 can be written as

$q=\frac{2 \pi r h k_{\mathrm{a}} k_{\mathrm{rg}}}{\bar{\mu}}\left(f_{\mathrm{c}}\right)\left(\frac{\mathrm{d} p}{\mathrm{~d} r}-G_{\mathrm{p}}\right)$

where $k_{\mathrm{rg}}$ can be calculated using the modified equation of Brooks and Corey (Eqs. 14 and 15) where $S_{\mathrm{w}}^{\prime}, S_{\mathrm{wc}}$ and $S_{\mathrm{gr}}$ are normalized water saturation, connate water saturation and residual gas saturation in fractions, respectively (Brooks and Corey 1964). 
$k_{\mathrm{rg}}=9.819 \times 10^{-1} \times\left(1-S_{\mathrm{w}}^{\prime}\right)^{1.269}\left(1-S_{\mathrm{w}}^{\prime 2}\right)$

$S_{\mathrm{w}}^{\prime}=\frac{S_{\mathrm{w}}-S_{\mathrm{wc}}}{1-\left(S_{\mathrm{wc}}+S_{\mathrm{gr}}\right)}$

Normally, in the case of gas, pseudo-pressure is used for accuracy which depends on gas deviation factor $(z)$ and viscosity $(\mu)$ of the gas

$m(p)=2 \int_{p m}^{p} \frac{p}{\mu z} \mathrm{~d} p$

$\frac{\mathrm{d} m}{\mathrm{~d} r}=2 \frac{p}{\mu z} \frac{\mathrm{d} p}{\mathrm{~d} r}$

So Eq. (13) becomes

$q=\frac{2 \pi r h k_{\mathrm{a}} k_{\mathrm{rg}}}{\bar{\mu}}\left(f_{\mathrm{c}}\right)\left[\left(\frac{\mu z}{2 p} \frac{\mathrm{d} m}{\mathrm{~d} r}\right)-G_{\mathrm{p}}\right]$

According to basic laws like gas state equation and equation of continuity

$q_{\mathrm{sc}}=q\left(\frac{z_{\mathrm{sc}} p T_{\mathrm{sc}}}{z T p_{\mathrm{sc}}}\right)$

where $z, p, T$ and $q$ are gas deviation factor, pressure, temperature and gas flow rate, respectively, and parameters with subscripts sc are the same parameters for gas but at standard conditions.

By solving Eqs. 18 and 19, and using average gas deviation factor $(z)$ and averages gas viscosity $(\mu)$, following equation can be obtained

$q_{\mathrm{sc}}=\frac{\pi h k_{\mathrm{a}} k_{\mathrm{rg}}}{\bar{\mu}}\left(f_{c}\right) \frac{1}{\ln \left(r_{\mathrm{D}}\right)}\left[\Delta\left(p^{2}\right)-2 \bar{p} G_{\mathrm{p}}(\Delta r)\right]\left(\frac{z_{\mathrm{sc}} T_{\mathrm{sc}}}{\bar{z} T p_{\mathrm{sc}}}\right)$

where

$\Delta\left(p^{2}\right)=p_{\mathrm{e}}^{2}-p_{\mathrm{w}}^{2}$

$\Delta r=r_{\mathrm{e}}-r_{\mathrm{w}}$

$r_{\mathrm{D}}=\frac{r_{\mathrm{e}}}{r_{\mathrm{w}}}$

$\Delta p=p_{\mathrm{e}}-p_{\mathrm{w}}$

where $\bar{p}$ is the average pressure (on plane radial flow basis) and is determined by the following equation:
$\bar{p}=p_{\mathrm{e}}-\frac{\Delta p}{2 \ln \left(r_{\mathrm{D}}\right)}$

Finally, after incorporating the gas Klinkenberg effect, Knudsen effect, gas rarefaction coefficient, slip coefficient and other basic parameters of gas state equation and equation of continuity, Eq. 20 is achieved where $G_{\mathrm{p}}$ was introduced into the model in Eq. 5. Since the experimental outputs of this study belong to the TPG $\left(G_{\mathrm{p}}\right)$ therefore, two mathematical equations are derived on the basis of these results, to fully describe the TPG in terms of absolute permeability (Eq. 2) and water saturation (Eq. 4).

Hence, considering the TPG in terms of absolute permeability and in terms of water saturation, the tight gas flow production models can be shown as Eqs. 22 and 23, respectively;

$$
\begin{aligned}
q_{\mathrm{sc}}= & \frac{\pi h k_{\mathrm{a}} k_{\mathrm{rg}}}{\bar{\mu}} \frac{z_{\mathrm{sc}} T_{\mathrm{sc}}}{\bar{z} T p_{\mathrm{sc}}}(1+\alpha(K n) K n)\left(1+\frac{4 K n}{1-b K n}\right) \frac{1}{\ln \left(r_{\mathrm{D}}\right)} \\
& \times\left[\Delta\left(p^{2}\right)-2 \bar{p}\left\{\left(9.69 \times 10^{-4} k_{\mathrm{a}}^{-0.2741}\right) p_{\mathrm{f}}^{\left(0.02371 k_{\mathrm{a}}^{-0.3407}\right)}\right\}(\Delta r)\right]
\end{aligned}
$$

$$
\begin{aligned}
q_{\mathrm{sc}}= & \frac{\pi h k_{\mathrm{a}} k_{\mathrm{rg}}}{\bar{\mu}} \frac{z_{s c} T_{\mathrm{sc}}}{\bar{z} T p_{s c}}(1+\alpha(K n) K n)\left(1+\frac{4 K n}{1-b K n}\right) \frac{1}{\ln \left(r_{\mathrm{D}}\right)} \\
& \times\left[\Delta\left(p^{2}\right)-2 \bar{p}\left\{\left(4 \times 10^{-3} S_{\mathrm{w}}+0.5 \times 10^{-3}\right) p_{\mathrm{f}}^{\left(0.04 S_{\mathrm{w}}-0.121\right)}\right\}(\Delta r)\right]
\end{aligned}
$$

\section{Validation and application}

For the validation of proposed production models considering TPG effects in addition to diffusion and slip flow effects of a tight reservoir (Eqs. 22 and 23), actual reservoir data of a zone of Peer gas field are used (Table 3). For the comparative analysis, the results obtained from these proposed models are compared with that from the model established

Table 3 Peer gas reservoir parameters

\begin{tabular}{ll}
\hline Parameter & Value \\
\hline Boundary pressure $p_{\mathrm{e}}, \mathrm{MPa}$ & 32 \\
Reservoir temperature $T, \mathrm{~K}$ & 357 \\
Reservoir thickness $h, \mathrm{~m}$ & 8.5 \\
Boundary radius $r_{\mathrm{e}}, \mathrm{m}$ & 180 \\
Well radius $r_{\mathrm{w}}, \mathrm{m}$ & 0.107 \\
Gas deviation factor $z$ & 0.96 \\
Gas viscosity $\mu, \mathrm{mPa} \mathrm{s}$ & 0.0168 \\
Collision diameter of gas molecule $\sigma, \mathrm{nm}$ & 0.4 \\
Pore throat radius $r, \mu \mathrm{m}$ & 0.015 \\
Connate water saturation $S_{\mathrm{wc}}$ & 0.47 \\
Residual gas saturation $S_{\mathrm{gr}}$ & 0.19 \\
\hline
\end{tabular}




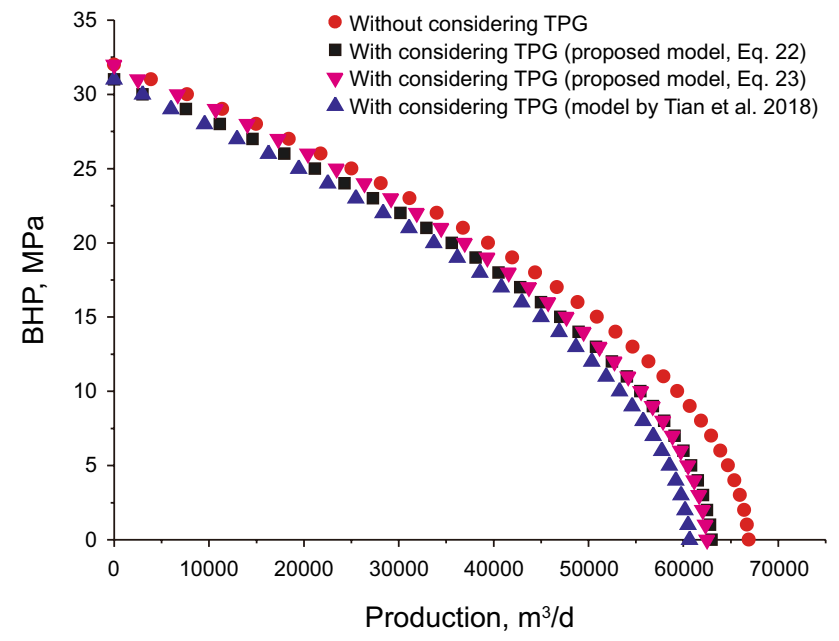

Fig. 9 Validation and comparison of proposed models
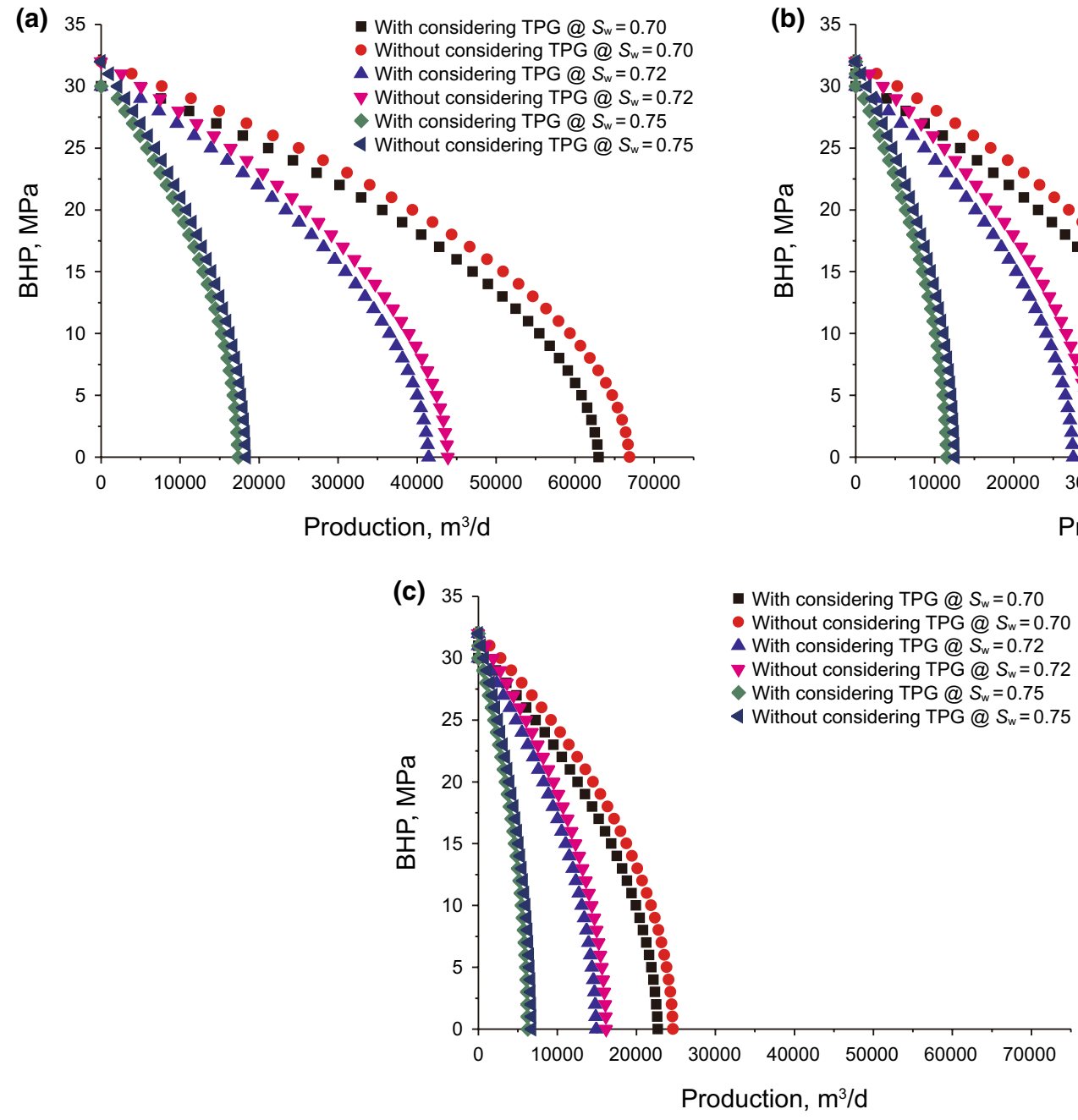

by Tian et al. (2018). Figure 9 shows that results from both the proposed models in this study are almost in agreement with the results from the Tian et al. model, where BHP is the abbreviation of bottom hole pressure. The results predicted by the Tian et al. model are a little bit lower because Tian et al. incorporated the effects of permeability and dimensionless water saturation in their mathematical correlation of TPG. However, in this study, beside the permeability and water saturation, the pore pressure is also included in the proposed mathematical correlations of TPG (Eqs. 2 and 4).

Inflow performance relationship (IPR) curves (Figs. 10 and 11) are generated using these proposed models which show that TPG greatly affects the gas flow rates at different drawdown pressures. It can be observed from Figs. 10 and 11 that the production rates are overestimated while ignoring the TPG.

Figure 10a shows the production profiles at constant permeability value $\left(0.095 \times 10^{-3} \mu^{2}\right)$ and at different water saturation $(0.70,0.72$, and 0.75$)$ with and without considering

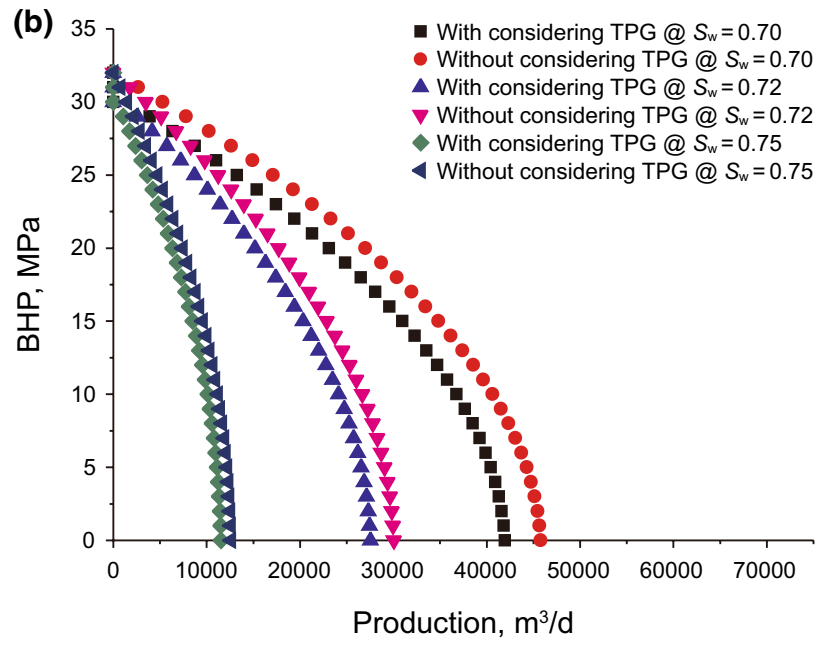

- Without considering TPG @ $S_{w}=0.70$

Without consid

With considering TPG @ $S_{w}=0.75$

Without considering TPG @ $S_{\mathrm{w}}=0.75$ 

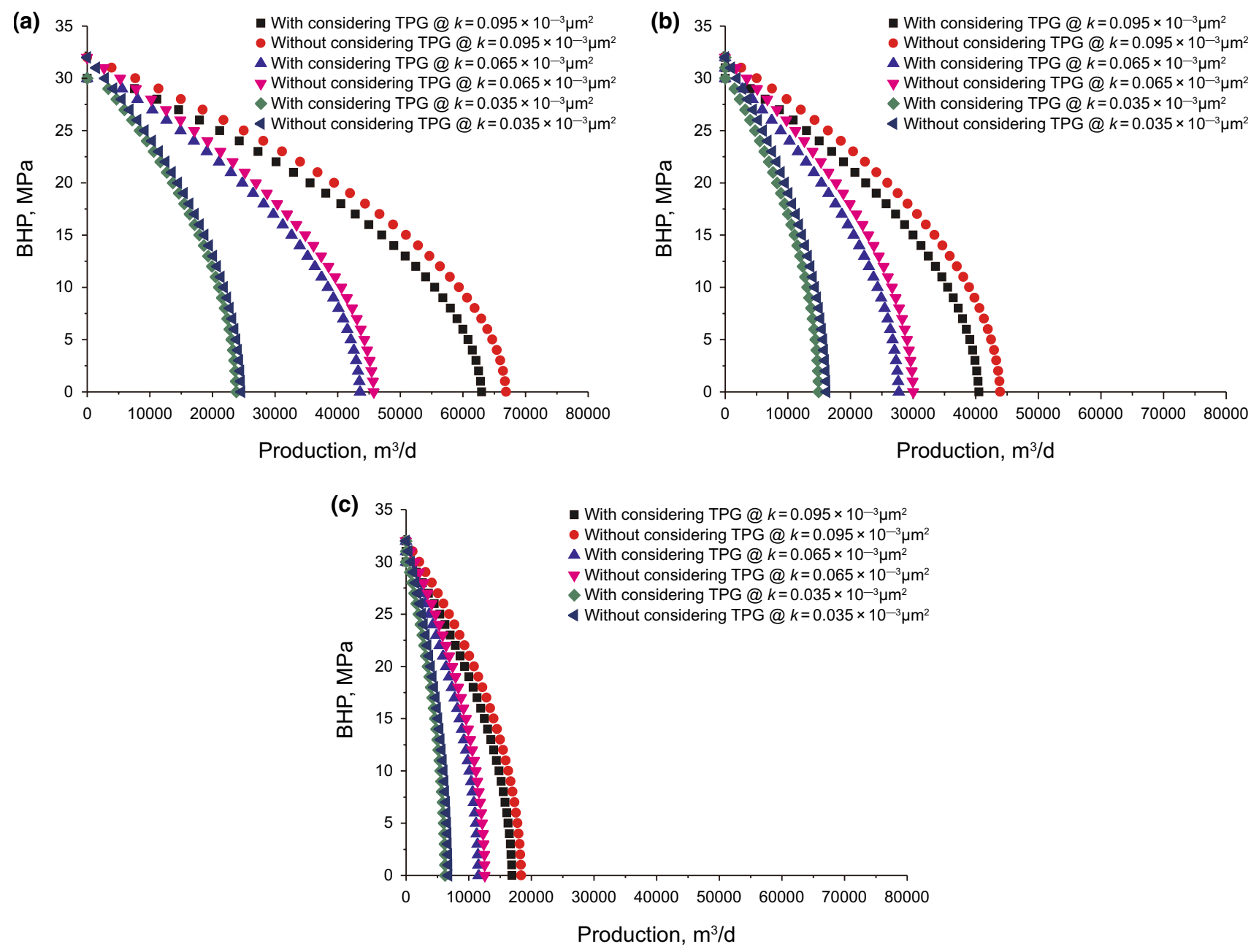

Fig. 11 IPR curves with and without considering TPG at the water saturation of a $0.70, \mathbf{b} 0.72$, and $\mathbf{c} 0.75$

TPG. Note that, the curves have the general trends that are: (1) at higher drawdown the gas production rates are higher; and (2) at lower water saturation the gas production rates are higher. However, with and without considering the TPG, the calculated gas production rates, at the same water saturation and same drawdown, are different. The similar behavior can also be seen from Fig. 10b and c which are at variable values of water saturation but constant permeability values of $0.065 \times 10^{-3} \mu \mathrm{m}^{2}$ and $0.035 \times 10^{-3} \mu \mathrm{m}^{2}$, respectively.

The similar behavior can also be seen from Fig. 11 where inflow performance relationship curves were generated at different permeability values $\left(0.095 \times 10^{-3} \mu \mathrm{m}^{2}\right.$, $0.065 \times 10^{-3} \mu \mathrm{m}^{2}$ and $0.035 \times 10^{-3} \mu \mathrm{m}^{2}$ ) and constant water saturation values of $0.70,0.72$ and 0.75 , respectively.

The absolute open flow potential of a gas well is defined as the maximum production rate by assuming the surface pressure at sand face (Li et al. 2018; Sinha and Padgett 1985). This parameter is used to compare the potential of production of different wells and based on this parameter many decisions are taken, i.e., completion designing and selection, surface equipment designing and selection, gas sale agreements, etc. (Li et al. 2017; Su et al. 2017).

Using the proposed production model, the absolute open flow potential (AOFP) is also compared as shown in Figs. 12 and 13. The maximum gas production rate can be achieved at the minimum bottom hole pressure (or maximum drawdown pressure). It can be observed from Fig. 12a that while considering TPG, the value of AOFP is around $62 \times 10^{3} \mathrm{~m}^{3} / \mathrm{d}$ which was around $66 \times 10^{3} \mathrm{~m}^{3} / \mathrm{d}$ when without considering the TPG, at the same permeability and water saturation values.

The scope of application of the proposed models is very vast. It can be applied for all tight to ultra-tight gas sandstone reservoirs. These proposed models calculate the corrected gas flow rate which is the most important parameter for tight gas sandstone field development in many ways such as, for generating outflow performance curves (OPR) which are based on IPR. Normally, well completion designing, i.e., 

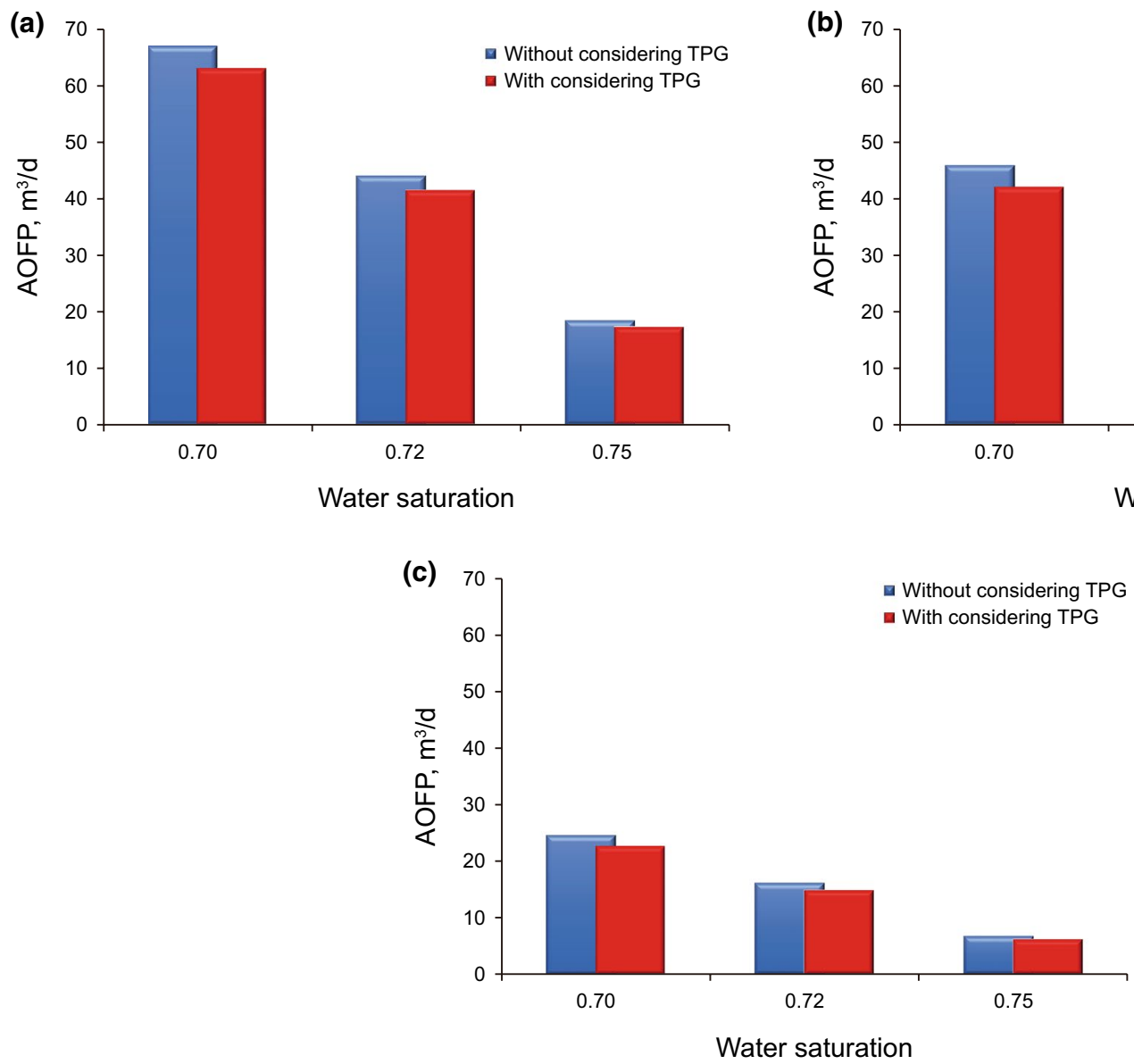

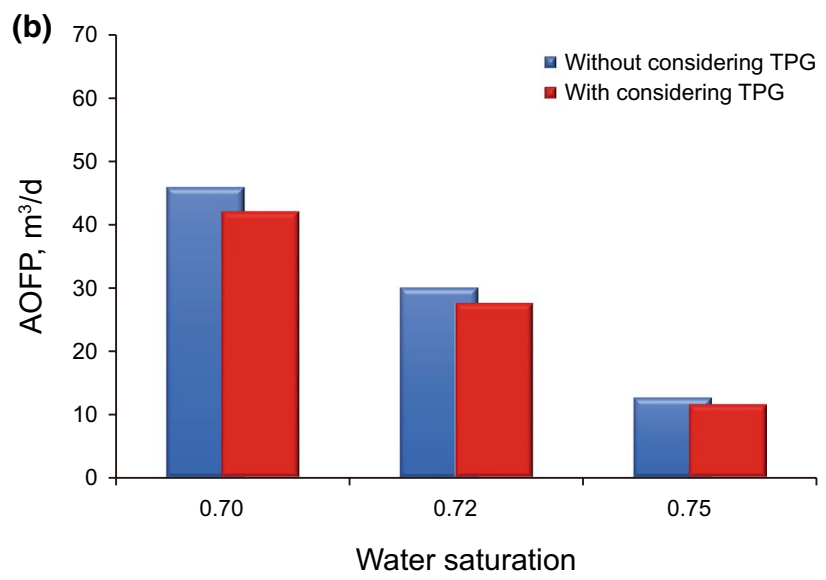

Fig. 12 AOFP with and without considering TPG at the permeability of $\mathbf{a} 0.095 \times 10^{-3}, \mathbf{b} 0.065 \times 10^{-3}$, and $\mathbf{c} 0.035 \times 10^{-3} \mu \mathrm{m}^{2}$

casing selection, tubing design, etc., is carried out on the basis of OPR (Hakiki et al. 2017). The skin factor is also a basic parameter that shows variation from predicted pressure drop due to skin. This factor is analytically modeled using the calculated gas flow rates (Dong et al. 2018; Li et al. $2018,2019 b)$. So, the corrected gas flow rate by incorporating the TPG is also very useful to calculate the skin factor.

\section{Conclusions}

In the tight gas sandstone reservoir, there exists TPG at lowvelocity flow profile. The value of TPG changes with the variations in pore pressure, permeability and water saturation. TPG increases in both cases either permeability decreases or water saturation increases. The value of TPG increases with the decrease in pore pressure by power relationship. During the production life of a reservoir, the pore pressure changes as the function of gas production and/or water encroachment; therefore, effects of the pore pressure on TPG are very important because these effects are dynamic and are representative of reservoir depletion mechanism.
Two definite mathematical correlations for TPG were obtained, considering the effects of pore pressure and permeability (Eq. 2), and depending on the influence of pore pressure and water saturation on TPG (Eq. 4). On the basis of these proposed mathematical correlations, gas production models were offered by incorporated the slip flow, diffusion flow and TPG (Eqs. 22 and 23). A comparative analysis of our models with the other previously published model supports the effectiveness of the approach presented in this study.

In order to analyze the application of the proposed models, inflow performance relationship curves were generated by using actual reservoir data. Note that, IPR is greatly affected by TPG. The effect of TPG on the calculation of AOFP was also studied. Comparisons show that AOFP is overestimated while ignoring the TPG. Generally, outflow relationship performance, well completion design, surface facilities design, field development plan, gas sale agreement, etc. are all directly linked to IPR and AOFP; hence, TPG should be considered to avoid overestimation of gas production rates for efficient and optimum field development of tight gas sandstone reservoirs. 


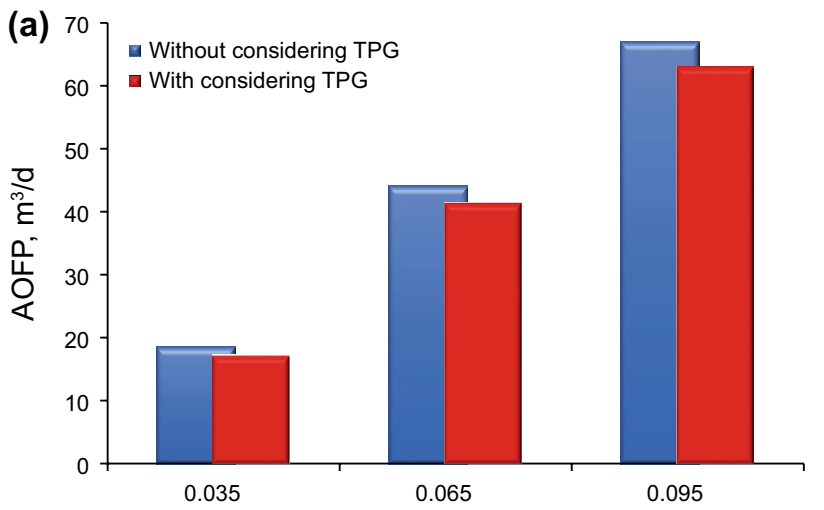

Permeability $k_{\mathrm{a}}, 10^{-3} \mu \mathrm{m}^{2}$

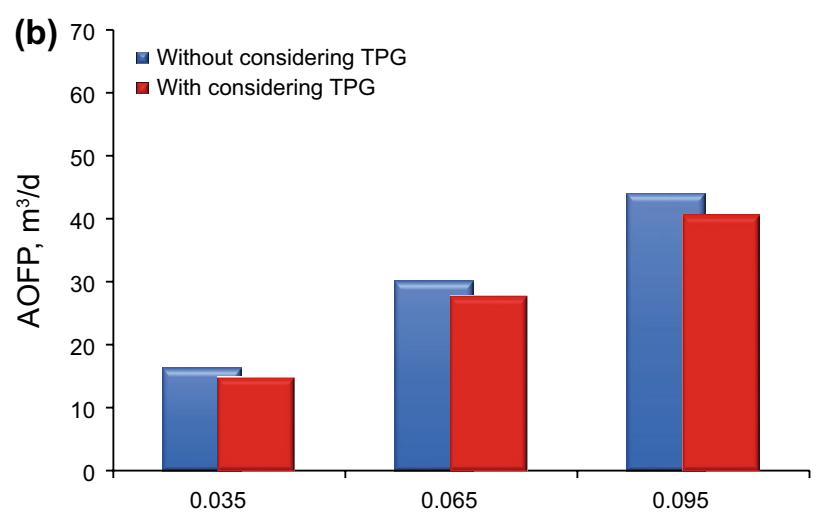

Permeability $k_{\mathrm{a}}, 10^{-3} \mu \mathrm{m}^{2}$

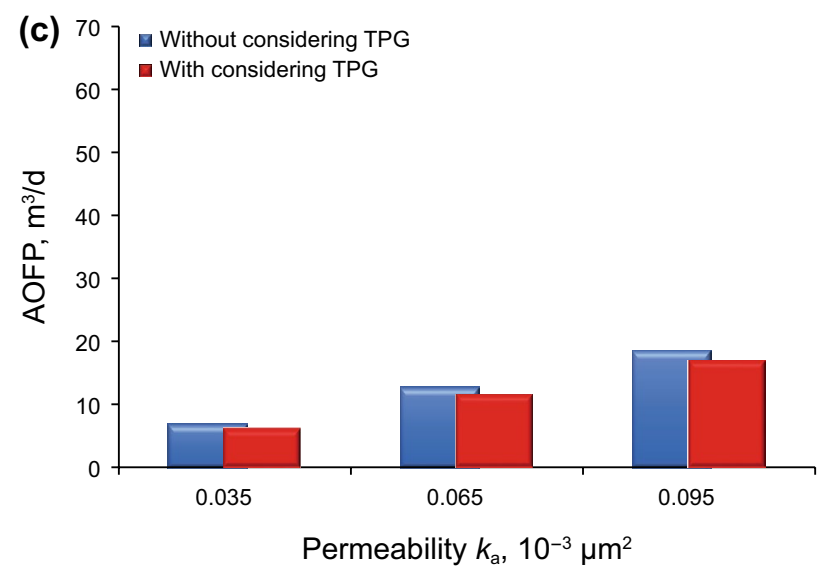

Fig. 13 AOFP with and without considering TPG at the water saturation of a $0.70, \mathbf{b} 0.72$, and $\mathbf{c} 0.75$

Acknowledgements This study was supported by the National Science Foundation (51674279, 51804328), Major National Science and Technology Project (2017ZX05009-001, 2017ZX05069, 2017ZX05072) Shandong Province Key Research and Development Program (2018GSF116004), Shandong Province Natural Science Foundation (ZR2018BEE008, ZR2018BEE018), Fundamental Research Funds for the Central Universities (18CX02168A), China Postdoctoral Science Foundation (2018M630813), Postdoctoral Applied Research Project Foundation of Qingdao city (BY201802003).

Open Access This article is licensed under a Creative Commons Attribution 4.0 International License, which permits use, sharing, adaptation, distribution and reproduction in any medium or format, as long as you give appropriate credit to the original author(s) and the source, provide a link to the Creative Commons licence, and indicate if changes were made. The images or other third party material in this article are included in the article's Creative Commons licence, unless indicated otherwise in a credit line to the material. If material is not included in the article's Creative Commons licence and your intended use is not permitted by statutory regulation or exceeds the permitted use, you will need to obtain permission directly from the copyright holder. To view a copy of this licence, visit http://creativecommons.org/licenses/by/4.0/.

\section{References}

Bennion DB, Thomas FB, Ma T. Recent advances in laboratory test protocols evaluate optimum drilling, completion and stimulation practices for low permeability gas reservoirs. In: SPE Rocky Mountain regional/low-permeability reservoirs symposium and exhibition, 12-15 March. Colorado; 2000. https://doi. org/10.2118/60324-MS.

Beskok A, Karniadakis GE. A model for flows in channels, pipes, and ducts at micro and nano scales. Microscale Thermophys Eng. 1999;3(1):43-77.

Brooks R, Corey T. Hydraulic properties of porous media. Hydrology papers. Fort Collins: Colorado State University; 1964.

Bird GA. Molecular Gas Dynamics. Oxford: Clarendon Press; 1976.

Cao L, Lu L, Li X, Wang H, He W, Deng Y, Jiang L. A composite transient model for multi-fractured horizontal well in tight gas reservoirs based on multi-factor effect. In: SPE Europec featured at 80th EAGE conference and exhibition, 11-14 June. Copenhagen, Denmark; 2018. https://doi.org/10.2118/190873-MS.

Chen Y, Durlofsky LJ. Adaptive local-global upscaling for general flow scenarios in heterogeneous formations. Transp Porous Media. 2006;62(2):157-85. https://doi.org/10.1007/s1124 2-005-0619-7. 
Civan F. Generalized Darcy's law by control volume analysis including capillary and orifice effects. J Can Pet Technol. 2008;47(10):1-7. https://doi.org/10.2118/08-10-01.

Civan F. Modeling gas flow through hydraulically-fractured shale-gas reservoirs involving molecular-to-inertial transport regimes and threshold pressure gradient. In: SPE annual technical conference and exhibition, 30 September-2 October. New Orleans; 2013.

Civan F. Effect of poroelasticity, pore confinement, molecular-toinertial transport, and threshold pressure on flow of gas through hydraulically-fractured shale-gas reservoirs. In: SPE annual technical conference and exhibition, 9-11 October. San Antonio; 2017. https://doi.org/10.2118/187056-MS.

Cussler EL. Diffusion mass transfer in fluid system. 2nd ed. Cambridge; 1997.

Deng J, Zhu W, Ma Q. A new seepage model for shale gas reservoir and productivity analysis of fractured well. Fuel. 2014;124:232-40. https://doi.org/10.1016/j.fuel.2014.02.001.

Diwu P, Liu T, You Z, Jiang B, Zhou J. Effect of low velocity nonDarcy flow on pressure response in shale and tight oil reservoirs. Fuel. 2018;216:398-406. https://doi.org/10.1016/j. fuel.2017.11.041.

Dong W, Wang X, Wang J. A new skin factor model for partially penetrated directionally-drilled wells in anisotropic reservoirs. J Pet Sci Eng. 2018;161:334-48. https://doi.org/10.1016/j.petro 1.2017.11.062.

Dong M, Yue X, Shi X, Ling S, Zhang B, Li X. Effect of dynamic pseudo threshold pressure gradient on well production performance in low-permeability and tight oil reservoirs. J Pet Sci Eng. 2019;173:69-766. https://doi.org/10.1016/j.petrol.2018.09.096.

Feng G, Liu Q, Shi G. An unsteady seepage flow model considering kickoff pressure gradient for low-permeability gas reservoirs. Pet Explor Dev. 2008;35(4):457-61. https://doi.org/10.1016/S1876 -3804(08)60094-4.

Hakiki F, Aditya A, Ulitha DT, Shidqi M, Adi WS, Wibowo KH, Barus $\mathrm{M}$. Well and inflow performance relationship for heavy oil reservoir under heating treatment. In: SPE/IATMI Asia Pacific oil \& gas conference and exhibition. 17-19 October. Jakarta, Indonesia; 2017. https://doi.org/10.2118/186187-MS.

Klinkenberg LJ. The permeability of porous media to liquid and gases. In: API drilling and production practice. 01 January. New York; 1941.

Li A, Zhang S, Liu M. A new method of measuring starting pressure for low permeability reservoir. J China Univ Pet. 2008;32(1):68-72.

Li CH, Li XZ, Gao SS, Liu HX, You SQ, Fang FF, Shen WJ. Experiment on gas-water two-phase seepage and inflow performance curves of gas wells in carbonate reservoirs: A case study of Longwangmiao Formation and Dengying Formation in GaoshitiMoxi block, Sichuan Basin SW China. Pet Explor Dev. 2017;44(6):930 8. https://doi.org/10.1016/S1876-3804(17)30110-6.

Li XZ, Liu XH, Su YH, Wu GM, Liu HX, Liu LL, Wan YJ, Guo ZH, Shi S. Correlation between per-well average dynamic reserves and initial absolute open flow potential (AOFP) for large gas fields in China and its application. Pet Explor Dev. 2018;45(6):1088-93. https://doi.org/10.1016/S1876-3804(18)30111-3.

Li JJ, Liu Y, Gao YJ, Cheng BY, Jiang HQ. Pore-scale study of the pressure-sensitive effect of sandstone and its influence on multiphase flows. Pet Sci. 2019a;16:382-95. https://doi.org/10.1007/ s12182-018-0266-6.

Li Y, Guo J, Wang S. The damage mechanisms of fracturing fluid on production in tight gas reservoirs. Energy Procedia. 2019b;158:5988-93. https://doi.org/10.1016/j.egypr o.2019.01.521.

Liang L, Xiong J, Liu X. An investigation into the thermodynamic characteristics of methane adsorption on different clay minerals. J Nat Gas Sci Eng. 2016;33:1046-55. https://doi.org/10.1016/j. jngse.2016.06.024.
Liu W. Analytical study on a moving boundary problem of semispherical centripetal seepage flow of Bingham fluid with threshold pressure gradient. Int J Non-Linear Mech. 2019. https://doi. org/10.1016/j.ijnonlinmec.2019.03.011.

Liu HH, Georgi D, Chen J. Correction of source-rock permeability measurements owing to slip flow and Knudsen diffusion: a method and its evaluation. Pet Sci. 2018;15:116-25. https://doi. org/10.1007/s12182-017-0200-3.

Liu W, Zhang Q, Zhu W. Numerical simulation of multi-stage fractured horizontal well in low-permeable oil reservoir with threshold pressure gradient with moving boundary. J Pet Sci Eng. 2019;178:1112-27. https://doi.org/10.1016/j.petrol.2019.04.033.

Loyalka SK, Hamoodi SA. Poiseuille flow of a rarefied gas in a cylindrical tube: solution of linearized Boltzmann equation. Phys Fluids A. 1990;2:2061-5. https://doi.org/10.1063/1.857681.

Miller RJ, Low PF. Threshold gradient for water flow in clay systems. Soil Sci Soc Am J. 1963;27(6):605-9. https://doi.org/10.2136/ sssaj1963.03615995002700060013x.

Moghaddam RN, Jamiolahmady M. Slip flow in porous media. Fuel. 2016;173:298-310. https://doi.org/10.1016/j.fuel.2016.01.057.

Nakhli A, Mbouga M, Bergaoui M, Khalfaoui M, Cretin M, Huguet P. Non-linear analysis in estimating model parameters for thymol adsorption onto hydroxyiron-clays. J Mol Liq. 2017;244:20110. https://doi.org/10.1016/j.molliq.2017.08.128.

Rezaee M, Rostami B, Pourafshary P. Heterogeneity effect on nonwetting phase trapping in strong water drive gas reservoirs. J Nat Gas Sci Eng. 2013;14:185-91. https://doi.org/10.1016/j. jngse.2013.06.012.

Sakhaee PA, Bryant SL. Effect of pore structure on the producibility of tight-gas sandstones. AAPG Bull. 2014;98(4):663-94. https ://doi.org/10.1306/08011312078.

Sinha MK, Padgett LR. Stabilized absolute open flow potential of a gas well. In: Sinha MK, Padgett LR, editors. Reservoir engineering techniques using Fortran. Dordrecht: D. Reidel; 1985.

Song H, Liu Q, Yang D, Yu M, Lou Y, Zhu W. Productivity equation of fractured horizontal well in a water-bearing tight gas reservoir with low-velocity non-Darcy flow. J Nat Gas Sci Eng. 2014;18:467-73. https://doi.org/10.1016/j.jngse.2014.03.022.

Su YH, Li XZ, Wan YJ, Zhang L, Liu XH, Liu HL. Research on connectivity evaluation methods and application for dolomite reservoir with fracture-cave. Nat Gas Geosci. 2017;28(8):1219-25. https://doi.org/10.11764/j.issn.1672-1926.2016.11.005.

Tian WB, Li AF, Ren XX, Josephine Y. The threshold pressure gradient effect in the tight sandstone gas reservoirs with high water saturation. Fuel. 2018;226:221-9. https://doi.org/10.1016/j. fuel.2018.03.192.

Wang X, Sheng JJ. Effect of low-velocity non-Darcy flow on well production performance in shale and tight oil reservoirs. Fuel. 2017a;190:41-6. https://doi.org/10.1016/j.fuel.2016.11.040.

Wang X, Sheng JJ. Gas sorption and non-Darcy flow in shale reservoirs. Pet Sci. 2017b;14:746-54. https://doi.org/10.1007/s 1218 2-017-0180-3.

Wang Z, Fink R, Wang Y, Hildenbrand AA, Kross BM, Wang M. Gas permeability calculation of tight rocks based on laboratory measurements with non-ideal gas slippage and poroelastic effects considered. Int J Rock Mech Min Sci. 2018;112:16-24. https://doi.org/10.1016/j.ijrmms.2018.10.002.

Wang J, Yu L, Yuan Q. Experimental study on permeability in tight porous media considering gas adsorption and slippage effect. Fuel. 2019;253:561-70. https://doi.org/10.1016/j. fuel.2019.05.048.

Wu K, Van DMIJ, Couples GD, Jiang Z, Ma J, Sorbie KS, Crawford J, Young I, Zhang X. 3D stochastic modelling of heterogeneous porous media-applications to reservoir rocks. Transp Porous Media. 2006;865(3):443-67. https://doi.org/10.1007/s1124 2-006-0006-z. 
Wu J, Cheng L, Li C, Cao R, Chen C, Cao M, Xu Z. Experimental study of nonlinear flow in micropores under low pressure gradient. Transp Porous Media. 2017;119:247-65. https://doi.org/10.1007/ s11242-017-0882-4.

Wu Z, Cui C, Lv G, Bing S, Cao G. A multi-linear transient pressure model for multistage fractured horizontal well in tight oil reservoirs with considering threshold pressure gradient and stress sensitivity. J Pet Sci Eng. 2019;172:839-54. https://doi.org/10.1016/j. petrol.2018.08.078.

Xiao L, Zou C, Xie H. A new method of evaluating tight sandstone reservoir pore structure from conventional logs. ASEG. 2016;1:1-6. https://doi.org/10.1071/ASEG2016ab106.

Xiong Y, Yu J, Sun H, Yuan J, Huang Z, Wu YS. A new non-Darcy flow model for low-velocity multiphase flow in tight reservoirs. Transp Porous Media. 2017;117:367-83. https://doi.org/10.1007/ s11242-017-0838-8.

Yan Q, He Q, Wei L, Qu Z, Ren XJ. A laboratory study on percolation characteristics of single phase flow in low-permeability reservoirs. Xi' an Pet Inst. 1990;5(2):1-6 (in Chinese).

Yang Z, Li X, Liu S. Threshold pressure effect of low permeability tight gas reservoirs in Sulige gas field. Acta Pet Sin. 2015;36(3):347-55 (in Chinese).

Yang D, Wang W, Chen W, Tan X, Wang L. Revisiting the methods for gas permeability measurement in tight porous medium. J Rock
Mech Geotech Eng. 2019;11(2):263-76. https://doi.org/10.1016/j. jrmge.2018.08.012.

Ye W, Wang X, Cao C, Yu W. A fractal model for threshold pressure gradient of tight oil reservoirs. J Pet Sci Eng. 2019;179:427-31. https://doi.org/10.1016/j.petrol.2019.04.039.

Zeng J, Wang X, Guo J, Zeng F, Zhang Q. Composite linear flow model for multi-fractured horizontal wells in tight sand reservoirs with the threshold pressure gradient. J Pet Sci Eng. 2018;165:890-912. https://doi.org/10.1016/j.petrol.2017.12.095.

Zhao Y, Zhang L, He Z, Zhang B. Productivity for horizontal wells in low permeability reservoir with oil/water two-phase flow. Math Probl Eng. 2014. https://doi.org/10.1155/2014/364678.

Zhou Y. Analytical solution for one-dimensional radial flow caused by line source in porous medium with threshold pressure gradient. Appl Math Model. 2019;67:151-8. https://doi.org/10.1016/j. apm.2018.10.024.

Zhu W, Song H, Huang X, Liu X, He D, Ren Q. Pressure characteristics and effective deployment in a water-bearing tight gas reservoir with low-velocity non-Darcy flow. Energy Fuels. 2011;25:1111-7. https://doi.org/10.1021/ef1014633. 